\title{
By-products of farmed European sea bass (Dicentrarchus labrax L.) as a potential source of n-3 PUFA
}

\author{
Concetta M. Messina ${ }^{1}$, Giuseppe Renda ${ }^{2}$, Laura LA BarberA $^{2}$ \& Andrea Santulli ${ }^{1,2}$ \\ ${ }^{1}$ University of Palermo, Dept. BIONEC, Section Biochemical Science, Marine Biochemistry Laboratory, Via Barlotta 4, \\ 91100 (TP), Italy; e-mail: concetta.messina@unipa.it \\ ${ }^{2}$ Marine Biology Institute, Consorzio Universitario della Provincia di Trapani, Via Barlotta 4, 91100 (TP), Italy
}

\begin{abstract}
Total by-products (TBP) obtained by filleting farmed and wild European sea bass (Dicentrarchus labrax) were analyzed to evaluate if, on the basis of the percentage yield, total lipid content and fatty acid composition, they can be considered a resource of n-3 polyunsaturated fatty acids (PUFA). Results show that TBP from intensively farmed fish (IFF) contain higher total lipid content and have a higher level of n-3 PUFA rich in eicosapentaenoic (EPA) and docosaexaenoic acid (DHA), compared to extensively farmed fish $(\mathrm{EFF})$ and to wild fish $(\mathrm{WF})(P<0.05)$. This difference may suggest a way of promotion of TBP from IFF sea bass through the n-3 PUFA recovery by extraction.
\end{abstract}

Key words: European sea bass; Dicentrarchus labrax; by-products; n-3 polyunsaturated fatty acids; PUFA

\section{Introduction}

The importance of the " $n-3$ series polyunsaturated fatty acids (PUFA)" in human and animal nutrition and in wellbeing and disease prevention is well recognized (Sahena et al. 2009). Eicosapentaenoic acid (EPA C20:5 n-3) and docosahexaenoic acid (DHA, C22:6 n-3) are the most important n-3 PUFA (Sargent et al. 2002; Sahena et al. 2009) and marine organisms are the main natural source of them (Kim \& Mendis 2006). The interest for n-3 PUFA and the decline in natural marine resources stimulated research to "find out" new sources alternative to fisheries, such as by-products originated from fish transformation industry and fisheries by-catch (Kim \& Mendis 2006; Ferraro et al. 2010; Patil \& Nag 2011). The European sea bass (Dicentrarchus labrax L., 1758) is one of the most important fish species farmed in the Mediterranean, for which new processed products, such as ready to cook fillets and heat induced gel products are recently developed in order to realize new market opportunities (Cardoso et al. 2012). These productions generate a significant percentage of by-products that need to be discarded in a controlled way, requiring a cost for both the producers and the environment. The alternative is to use it to extract bioactive compounds, such as peptides, oligosaccharides, fatty acids, enzymes, useful for biotechnological, pharmaceutical, nutraceutical applications and for fish oil, fishmeal, and fertilizer preparations (New \& Wijkström 2002; Bechtel \& Oliveira 2006; Kim \& Mendis 2006). Among these bioactive compounds, n-3 PUFA can be particularly represented (Kim \& Mendis 2006; Ferraro et al. 2010) in relation to species-specific and eco-physiological factors (Ackman 1995; Sargent et al. 2002).

The nutritional composition of wild and farmed sea bass and the effect of artificial diet on size, nutritional traits, including n-3 PUFA of fillet, are well known (Grigorakis 2007). On the contrary, no data are available on the composition of whole by-products of this species. In this study we analyzed for the first time the by-products (TBP) total compounds originating from filleting fish farmed in intensive (IFF) to evaluate if these items have the potential to be new sources of n-3 PUFAs to produce oil for food or nutraceutical industry. By-products from wild (WF) and fish farmed in extensive system (EFF) were analyzed for comparison.

\section{Material and methods}

\section{Sampling}

Farmed sea bass were obtained from a land intensive farm and from an extensive farm operating in a salt work, both located in Sicily (Italy). Wild sea bass (WF) were caught by gillnet in the same area and season (winter) in 2010. IFF were fed with a standard commercial extruded feed containing $45 \%$ of crude protein and $21 \%$ of fat. In the solar saltwork, EFF fish were cultured at a low density and not supplied with artificial diet. For each lot, 30 fish were collected and the standard biometric parameter recorded (Table 1).

Fillets and tissue representing by-products (TBP) were sampled, weighed (Table 2) and stored at $-80^{\circ} \mathrm{C}$ until analyses.

The fillet yield percentage was calculated as: total fillet without skin $(\mathrm{g}) /$ wet total body weight $(\mathrm{g}) * 100$

The TBP percentage was calculated as:

(skin+viscera+liver+head+skeleton) $(\mathrm{g}) /$ wet total body weight $(\mathrm{g}) * 100$. 
Table 1. Biometric parameters calculated in IFF, EFF and WF $(n=30)$.

\begin{tabular}{lrrr}
\hline & IFF & EFF & WF \\
\hline Weight (g) & $201.78 \pm 20.96^{a}$ & $167.69 \pm 19.27^{a}$ & $182.00 \pm 63.53^{a}$ \\
Standard length $(\mathrm{cm})$ & $24.21 \pm 0.91^{a}$ & $22.35 \pm 1.16^{b}$ & $22.56 \pm 3.03^{b}$ \\
K & $1.42 \pm 0.12^{b}$ & $1.5 \pm 0.09^{a b}$ & $1.53 \pm 0.11^{a}$ \\
\hline
\end{tabular}

Explanations: Data are expressed as mean \pm standard deviation. Means showing different letters within a row, are significantly different $(P<0.05)$. K (condition factor $)=$ wet body weight $(\mathrm{g}) / \operatorname{standard~length}^{3}(\mathrm{~mm}) * 100$.

Table 2. Percentage of fillet yield, TBP and fractions of by-products calculated in IFF, EFF and WF $(n=30)$.

\begin{tabular}{|c|c|c|c|}
\hline & IFF & $\mathrm{EFF}$ & WF \\
\hline Fillet yield (\%) & $40.39 \pm 3.20$ & $42.40 \pm 0.99$ & $43.22 \pm 3.29$ \\
\hline $\mathrm{TBP}(\%)$ & $56.55 \pm 1.02^{a}$ & $57.22 \pm 1.17^{a}$ & $53.47 \pm 1.93^{b}$ \\
\hline \multicolumn{4}{|l|}{ Fractions of by-products(\%) } \\
\hline Total viscera & $15.50 \pm 3.20^{a}$ & $15.74 \pm 2.0^{a}$ & $11.32 \pm 2.2^{b}$ \\
\hline Liver & $3.34 \pm 0.81^{a}$ & $2.27 \pm 0.43^{b}$ & $2.13 \pm 1.02^{b}$ \\
\hline Head, backbone, skin, trimming (pooled) & $79.45 \pm 2.03^{a}$ & $79.64 \pm 2.20^{a}$ & $84.12 \pm 3.30^{b}$ \\
\hline
\end{tabular}

Explanations: Data are expressed as mean \pm standard deviation. Means showing different letters within a row are significantly different $(P<0.05)$.

\section{Proximate composition}

TBP, for each specimens, were pooled, minced and analyzed in triplicate for moisture (drying at $105^{\circ} \mathrm{C}$ ), crude protein (Kjeldhal method), ash (ignition at $600^{\circ} \mathrm{C}$ for 5 hours), total lipid content (Folch et al. 1957). Lipids were dried by rotavapor, determined gravimetrically, then resuspended in $\mathrm{n}$-hexane and stored under nitrogen atmosphere at $-20^{\circ} \mathrm{C}$ until analysis.

\section{Lipid class composition}

Total lipids were separated by absorption chromatography on a silica column using chloroform to elute triglycerides (TG) and methanol to elute phospholipids (PL). The fractions were determined by gravimetric method.

The total cholesterol content was assayed by colorimetric method employing a commercial kit (Globe Diagnostics S.r.l., Italy).

\section{Lipid peroxidation assay}

The lipid peroxidation was evaluated by spectrophotometric determination of thiobarbituric acid reactive substances (TBARS) and was expressed as concentration of malondialdeyde (MDA) (Burk et al. 1980).

\section{Fatty acids analyses}

Fatty acids methyl esters (FAMEs) were obtained from the total lipids by the method of Lepage \& Roy (1984), dissolved at $1 \%$ in ciclo-exane and analyzed by gas chromatography. The instrument was a Perkin Helmer autosystem XL equipped with a silica capillary column $(30 \mathrm{~m} \times 0.32 \mathrm{~mm} \times$ $0.25 \mu \mathrm{m}$ Omegawax 320, Supelco, Bellefonte, PA, USA) and a flame ionization detector. Helium was used as the carrier gas $\left(25 \mathrm{~cm} \mathrm{~s}^{-1}\right)$. The column temperature was programmed at $200^{\circ} \mathrm{C}$, injector and detector were maintained at $250{ }^{\circ} \mathrm{C}$ and $300^{\circ} \mathrm{C}$, respectively. Individual FAMEs were identified by comparison of known standard (mix PUFA of fish oil, Supelco, Bellefonte, PA, USA).

\section{Statistical analysis}

Data are reported as mean values \pm standard deviation (SD). One-way analysis of variance (ANOVA) was performed and Tukey was used as post hoc test for comparison of the means among samples. Significance was accepted at probabilities $P<0.05$. Analyses were performed by STATISTICA version 6.0.

\section{Results and discussion}

\section{TBP physico-chemical characterization}

The utilization of fish processed by-products as raw material to obtain n-3 PUFA needs a preliminary study to verify the quality of by-products obtained in terms of yield and biochemical composition (Malone et al. 2004), variable in relation to the species, type of discarded tissue and environmental factors (Malone et al. 2004; Falch et al. 2006).

In our study, IFF and EFF specimens showed a higher percentage of discarded tissue compared to WF $(P<0.05)$ (Table 2). Our results are in conformity with data observed for the same species by Poli et al. (2001) and similar to those obtained from other fish species processed for fish oil production, such as gadiform (Falch et al. 2006) and Alaskan processed seafood (Oliveira \& Bechtel 2005).

Among the tissues representing by-products, the fraction composed by head, backbone, skin, trimming is most represented in TBP of WF in comparison with IFF and EFF $(P<0.05)$ (Table 2).

The fish heads and trimming resulting from processing were employed for oil production from Alaskan processed seafood (Oliveira \& Bechtel 2005) and tuna fish (Chantachum et al. 2000; Selmi et al. 2008). In particular, fish head and liver have long been a source of fish oil and consumed to improve vision and growth (Selmi et al. 2008).

In our study, the viscera and liver fractions are highest, as expected for the effect of artificial diet, in TBP obtained from IFF $(P<0.05)$ (Table 2 ); the values were comparable to data reported for the same species by Grigorakis (2007) and for hilsa fish by Patil \& Nag 
Table 3. Proximate composition (g/100g of wet weight) of TBP of IFF, EFF and WF $(n=30)$.

\begin{tabular}{lrrr}
\hline$\%$ & IFF & EFF & WF \\
\hline Water & $58.15 \pm 3.27^{a}$ & $61.59 \pm 1.68^{b}$ & $64.8 \pm 2.64^{c}$ \\
Crude protein & $15.58 \pm 1.68^{a}$ & $16.06 \pm 0.69^{a}$ & $16.6 \pm 0.87^{a}$ \\
Ash & $7.12 \pm 1.07^{a}$ & $7.50 \pm 1.47^{a}$ & $7.81 \pm 1.56^{a}$ \\
Total lipids & $16.24 \pm 3.03^{a}$ & $14.07 \pm 1.82^{a}$ & $9.55 \pm 2.14^{b}$ \\
\hline
\end{tabular}

Explanations: Data are expressed as mean \pm standard deviation. Means showing different letters within a row are significantly different $(P<0.05)$.

Table 4. Total lipid content (g/100g of wet weight) of fraction representing by-products in IFF, EFF and WF $(n=30)$.

\begin{tabular}{lrrr}
\hline & IFF & EFF & WF \\
\hline Viscera & $44.12 \pm 1.2^{a}$ & $36.12 \pm 0.68^{b}$ & $29.34 \pm 0.74^{c}$ \\
Liver & $26.24 \pm 3.82^{a}$ & $23.18 \pm 2.87^{a}$ & $12.5 \pm 2.87^{b}$ \\
Head,backbone, skin, trimming & $15.58 \pm 1.68^{a}$ & $13.11 \pm 0.39^{b}$ & $10.76 \pm 0.47^{c}$ \\
\hline
\end{tabular}

Explanations: Data are expressed as mean \pm standard deviation. Means showing different letters within a row are significantly different $(P<0.05)$.

Table 5. Triglycerides, phospholipids, total cholesterol (g/100 g of total lipids) and TBARS (mg MDA/1000 g of total lipids) contained in total lipids of TBP of IFF, EFF and $\operatorname{WF}(n=30)$.

\begin{tabular}{lrrr}
\hline & IFF & EFF & WF \\
\hline Triglycerides & $87.25 \pm 3.42^{a}$ & $80.05 \pm 1.24^{b}$ & $75.40 \pm 2.44^{c}$ \\
Phospholipids & $10.47 \pm 3.37^{a}$ & $18.99 \pm 5.23^{b}$ & $20.69 \pm 3.23^{b}$ \\
Total cholesterol & $1.97 \pm 0.81^{a}$ & $1.88 \pm 0,25^{a}$ & $1.67 \pm 0,22^{a}$ \\
TBARS & $3.08 \pm 1.63^{a}$ & $1.75 \pm 0.69^{a}$ & $1.52 \pm 0.71^{a}$ \\
\hline
\end{tabular}

Explanations: Data are expressed as mean \pm standard deviation. Means showing different letters within a row are significantly different $(P<0.05)$.

(2011). Variable data of viscera percentage are reported for pollock and salmon fishes used for the same purpose (Oliveira \& Bechtel 2005).

Regarding the crude composition of TBP, both lots of reared sea bass showed higher total lipid content compared to wild $(P<0.05)$ (Table 3$)$ as a results of the strong relationship between the dietary energy/lipid levels of the artificial diet and the lipid deposition (Sargent et al. 2002). This aspect is also well known for sea bass (Grigorakis 2007).

The total protein and the ash percentage content were equal among the analyzed samples and the water content showed an opposite trend with respect to the total lipids amount (Table 3), as generally observed in fish (Sargent et al. 2002). Similar results in terms of crude composition were observed in herring and in gadiform fish by-products utilized for fish oil production (Aidos et al. 2002; Falch et al. 2006). A study carried out on catfish by-products presented higher total lipid content due to the exclusive utilization of viscera (Sathivel et al. 2002).

\section{TPB lipid profiles}

The total lipid content was also evaluated in separated fractions of by-products (Table 4). Results showed a higher total lipid content in all fractions isolated from IFF fish compared to fractions obtained from EFF and WF $(P<0.05)$. As expected, the visceral and liver fractions presented the highest total lipid content (Table 4) being tissues devoted to lipid deposition (Sargent et al. 2002). The lipid content range reported for these fractions essentially depended on the species of origin, e.g., in Alaskan species utilized for oil production (Oliveira \& Bechtel 2005).

Because of limited incidence of viscera and liver in the TBP of sea bass and in order to have immediate information on the possibilities of exploitation of the whole by-products obtained from processing, in this work we analyzed the lipid classes and the fatty acid profile only in the pooled TBP.

The analyses of the lipid classes of TBP showed that TG are most represented in all samples, with the highest value in IFF followed by EFF and WF (Table 5). PL presented an opposite trend and both percentage and observed trends (Table 5) were in accordance to data reported for fish employed for the same purpose, such as Alaskan species (Oliveira \& Bechtel 2005).

Analyses of fatty acid profile of total lipids showed that TBP of IFF were characterized by higher n-3 PUFA than in EFF and WF $(P<0.05)$, in which the predominant classes were monounsaturated and saturated fatty acids (Fig. 1).

The analysis of fatty acids profile showed that with regard to the incidence of essential fatty acids, TBP of IFF were characterized by higher content of DHA than WF and $\operatorname{EFF}(P<0.05)$ (Fig. 2). The content of EPA was also higher in TBP of IFF and WF fish 


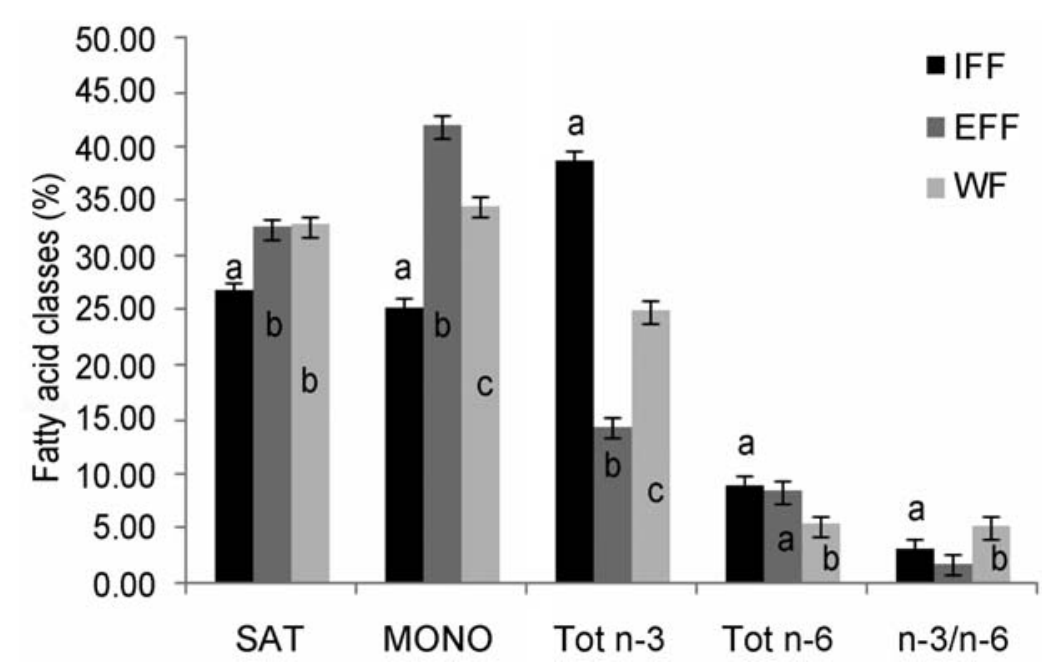

Fig. 1. Fatty acid classes (\%) in total lipids of TBP of IFF, EFF and WF $(n=30)$. Data are expressed as mean \pm standard deviation. Means showing different letters are significantly different $(P<0.05)$.

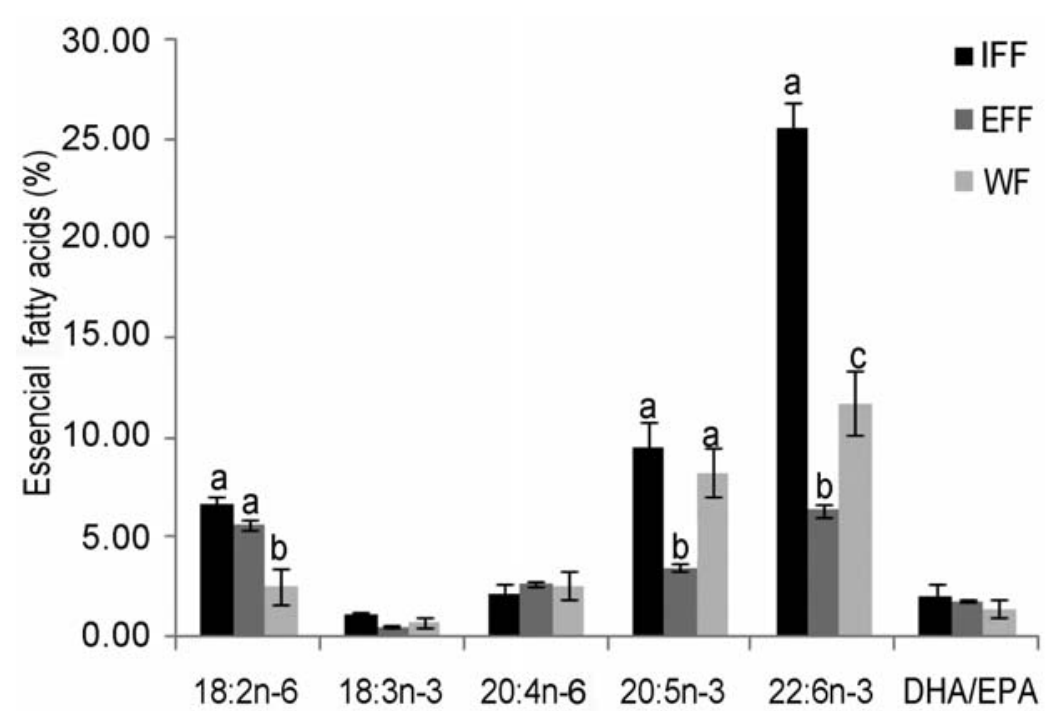

Fig. 2. Essential fatty acid (\%) in total lipid of TBP of IFF, EFF and WF $(n=30)$. Data are expressed as mean \pm standard deviation. Means showing different letters are significantly different $(P<0.05)$.

than in EFF samples (Fig. 2) $(P<0.05)$. If expressed in terms of grams of fatty acids, the analyses showed that per $100 \mathrm{~g}$ of TBP obtained from sea bass farmed in intensive system it is possible to recover $3.6 \mathrm{~g}$ of DHA in comparison to $0.84 \mathrm{~g}$ and $1.05 \mathrm{~g}$ from EFF and WF, respectively (Table 6) and $1.37 \mathrm{~g}$ of EPA in comparison to the lower amounts obtained from TBP of EFF and WF (0.47 g and $0.7 \mathrm{~g}$, respectively) $(P<$ 0.05) (Table 6).

Similar results were observed in catfish (Sathivel et al. 2002), Atlantic salmon (Sun et al. 2002), and shrimp processing by-products (Heu et al. 2003), showing the high potential of by-products obtained from intensively farmed fish as raw material for PUFA extraction.

The incidence of n-3 PUFA and the percentage of EPA and DHA in particular, are often considered as a fundamental factor in evaluating the possibility of using by-products from processed fish species as a source of n-3 PUFA.
Viscera of farmed Atlantic salmon having a $27 \%$ of EPA+DHA were proposed as source of n-3 PUFA (Sun et al. 2002); variable amounts of these fatty acids were observed in by-products of haddock species (Malone et al. 2004); the Nile perch was also considered as a source of by-products for n-3 PUFA even if it showed a low yield of EPA and DHA (Turon et al. 2005); a study carried out on by-products of various gadiform species showed that the levels of EPA and DHA varied between the fractions of by-products and species analyzed, being higher in trimming and liver due to the effect of fishing season and feeding behavior (Falch et al. 2006). Variable percentage of EPA and DHA were observed in fish oil obtained from commercial Alaskan fish by-products (Oliveira \& Bechtel 2005; Bechtel \& Oliveira 2006) and tuna by-products (Chantachum et al. 2000; Selmi et al. 2008).

Regarding farmed fish, commercial diets provide a well-balanced n-3 PUFA content, vitamins and antioxi- 
Table 6. Fatty acid content, as g/100 g of wet tissue, in TBP of IFF, EFF and WF $(n=30)$.

\begin{tabular}{|c|c|c|c|}
\hline Fatty acids & IFF & $\mathrm{EFF}$ & WF \\
\hline 14:0 & $0.32 \pm 0.01^{a}$ & $0.48 \pm 0.05^{a}$ & $0.25 \pm 0.04^{b}$ \\
\hline $16: 0$ & $2.69 \pm 0.29^{a}$ & $3.07 \pm 0.17^{a}$ & $2.00 \pm 0.15^{b}$ \\
\hline $16: 1 \mathrm{n}-7$ & $0.55 \pm 0.08^{a}$ & $1.49 \pm 0.09^{b}$ & $0.63 \pm 0.06^{a}$ \\
\hline $16: 2 n-4$ & $0.04 \pm 0.01^{a}$ & $0.15 \pm 0.01^{b}$ & $0.07 \pm 0.01^{a}$ \\
\hline $16: 3 n-4$ & $0.07 \pm 0.01^{a}$ & $0.17 \pm 0.02^{b}$ & $0.08 \pm 0.03^{a}$ \\
\hline 18:0 & $0.81 \pm 0.14^{a}$ & $0.71 \pm 0.05^{b}$ & $0.48 \pm 0.04^{c}$ \\
\hline $18: 1 \mathrm{n}-9$ & $2.56 \pm 0.10^{a}$ & $3.13 \pm 0.15^{b}$ & $1.68 \pm 0.10^{c}$ \\
\hline $18: 1 \mathrm{n}-7$ & $0.24 \pm 0.02^{a}$ & $0.75 \pm 0.03^{b}$ & $0.38 \pm 0.08^{a}$ \\
\hline $18: 2 \mathrm{n}-6$ & $0.96 \pm 0.05^{a}$ & $0.75 \pm 0.10^{a}$ & $0.21 \pm 0.08^{b}$ \\
\hline $18: 3 n-4$ & nd & nd & nd \\
\hline $18: 3 n-3$ & $0.16 \pm 0.03^{a}$ & $0.08 \pm 0.02^{b}$ & $0.06 \pm 0.02^{b}$ \\
\hline $18: 4 n-3$ & $0.11 \pm 0.04^{a}$ & $0.05 \pm 0.01^{b}$ & $0.06 \pm 0.02^{b}$ \\
\hline $20: 1 n-9$ & $0.17 \pm 0.03^{a}$ & $0.14 \pm 0.02^{a}$ & $0.09 \pm 0.01^{b}$ \\
\hline $20: 4 n-6$ & $0.31 \pm 0.08^{a}$ & $0.35 \pm 0.04^{a}$ & $0.22 \pm 0.06^{b}$ \\
\hline $20: 4 n-3$ & $0.04 \pm 0.01^{a}$ & $0.04 \pm 0.02^{a}$ & $0.03 \pm 0.01^{a}$ \\
\hline $20: 5 n-3$ & $1.37 \pm 0.25^{a}$ & $0.47 \pm 0.07^{b}$ & $0.70 \pm 0.12^{c}$ \\
\hline $22: 1 \mathrm{n}-11$ & nd & nd & nd \\
\hline $22: 1 n-9$ & nd & nd & nd \\
\hline $22: 4 n-6$ & nd & $0.10 \pm 0.03^{a}$ & $0.07 \pm 0.04^{b}$ \\
\hline $22: 5 n-3$ & $0.17 \pm 0.07^{a}$ & $0.40 \pm 0.11^{b}$ & $0.23 \pm 0.09^{c}$ \\
\hline $22: 6 \mathrm{n}-3$ & $3.67 \pm 0.22^{a}$ & $0.84 \pm 0.21^{b}$ & $1.05 \pm 0.23^{b}$ \\
\hline $24: 1 \mathrm{n}-9$ & nd & nd & nd \\
\hline Saturated & $3.82 \pm 0.31^{a}$ & $4.27 \pm 1.12^{a}$ & $2.74 \pm 0.74^{b}$ \\
\hline Mono & $3.61 \pm 0.12^{a}$ & $5.51 \pm 1.34^{b}$ & $2.83 \pm 0.65^{c}$ \\
\hline PUFA n-3 & $5.49 \pm 0.16^{a}$ & $1.83 \pm 0.88^{b}$ & $2.10 \pm 0.11^{b}$ \\
\hline PUFA n-6 & $1.27 \pm 0.22^{a}$ & $1.20 \pm 0.56^{a}$ & $0.49 \pm 0.12^{b}$ \\
\hline
\end{tabular}

Explanations: Data are expressed as mean \pm standard deviation. Means showing different letters within a row are significantly different $(P<0.05)$.

dants due to the inclusion of marine oils, directly influencing the nutritional traits and fatty acid composition of fillets (Cahu et al. 2004). In addition, our results indicate that artificial diet can also influence the TBP of IFF fish, as demonstrated by the high recovery of n-3 PUFA in comparison to EFF and WF, and by the low levels of MDA, a marker of fish oil peroxidation (Gonzales et al. 1992), despite the higher total lipid content and n-3 PUFA content (Table 5, Fig. 1).

These data can be useful to plan an industrial utilization of TBP from farmed sea bass and for oil extraction and n-3 PUFA purification, useful for the production of fish oil or supplements. This possibility can bring a series of benefits both for farmers and the environment: for farmers by adding value to the waste, avoiding the expenses of its disposal, and for environment by recycling n-3 PUFA, thus reducing pressure on natural resources.

\section{Conclusion}

The possibility to use raw materials obtained from the processing of farmed fish, such as European sea bass, compared to the utilization of by-products from fisheries, can guarantee a certain constant yield and biochemical composition due to the remarkable effects of artificial diet on merchantable traits and body composition. In addition, the knowledge of the quantity of processed fish/year in an industrial fish farm can permit to forecast the quantity of by-products/oil produced.

\section{Acknowledgements}

This study was supported by grants from Italian Ministry of Education, University and Research, University of Palermo: cod. ORPA07ARYE, cod. ORPA07P53E.

\section{References}

Aidos I., Masbernat-Martinez S., Luten J.B., Boom R.M. \& Van der Padt A. 2002. Composition and stability of herring oil recovered from sorted byproducts as compared to oil from mixed byproducts. J. Agric. Food Chem. 50 (10): 2818-2824. DOI: $10.1021 /$ jf011318t

Bechtel P.J. \& Oliveira A.C.M. 2006. Chemical characterization of liver lipid and protein from cold-water fish species. J. Food Sci. 71 (6): $\overline{480}-485$. DOI: $10.1111 / \mathrm{j} \cdot 1750-38 \overline{41.2006} .00076 . x$

Cahu C., Salen P. \& de Lorgeril M. 2004. Farmed and wild fish in the prevention of cardiovascular diseases: assessing possible differences in lipid nutritional values. Nutr. Metab. Cardiovasc. Dis. 14 (1): 34-41. DOI: 10.1016/S09394753(04)80045-0

Cardoso C.L., Mendes R.O., Vaz-Pires P. \& Nunes M.L. 2012. Quality differences between heat-induced gels from farmed gilthead sea bream (Sparus aurata) and sea bass (Dicentrarchus labrax). Food Chem. 131 (2): 660-666. DOI: 10.1016/j.foodchem.2011.09.051

Chantachum S., Benjakul S. \& Sriwirat N. 2000. Separation and quality of fish oil from precooked and non-precooked tuna heads. Food Chem. 69 (3): 289-294. DOI: 10.1016/S03088146(99)00266-6

Falch E., Rustad T \& Aursand M. 2006. By-products from gadiform species as raw material for production of marine lipids as ingredients in food or feed. Process Biochem. $41(3): 666-$ 67 $\overline{4}$. DOI: $10.101 \overline{6} / \mathrm{j}$.procbio.2005.08.015

Ferraro V., Cruz I.B., Jorge R.F., Malcata F.X., Pintado M.E. \& Castro P.M.L. 2010. Valorization of natural extracts from 
marine source focused on marine by-products: a review. Food Res. Int. 43 (9): 2221-2233. DOI: 10.1016/j.foodres.2010.07.034 Folch J., Lees M. \& Stanley G.H.S. 1957. A simple method for the isolation and purification of total lipids from animal tissues. J. Biol. Chem. 226: 497-509.

Grigorakis K. 2007. Compositional and organoleptic quality of farmed and wild gilthead sea bream (Sparus aurata) and sea bass (Dicentrarchus labrax) and factors affecting it: A review. Aquaculture 272 (1-4): 55-75 DOI: 10.1016/j.aquaculture.2007.04.062

Kim S. \& Mendis E. 2006. Bioactive compounds from marine processing by-products- A review. Food Res. Int. 39 (4): 383-393. DOI: 10.1016/j.foodres.2005.10.010

Lepage G. \& Roy C.C. 1984. Improved recovery of fatty acid through direct transesterification without prior extraction or purification. J. Lipid Res. 25: 1391-1396. PMID: 6530596

Malone C., Shaw N.B. \& Kerry J.P. 2004. Effect of season on Vitamin E, fatty acid profile, and nutritional value of fish byproducts from cod, saithe, ling and haddock species caught in Southern Irish coastal waters. J. Aquat. Food Prod. Techn. 13 (3): 127-149. DOI: 10.1300/J030v13n03_12

Oliveira A.C.M \& Bechtel P.J. 2005. Lipid composition of Alaska Pink Salmon (Onchorhynchus gorbuscha) and Alaska Walleye Pollock (Theragra chalcogramma) byproducts. J. Aquat. Food Prod. Techn. 14 (1): 73-91. DOI: 10.1300/J030v14n01_ 07
Patil D. \& Nag A. 2011. Production of PUFA concentrates from poultry and fish processing waste. J. Am. Oil Chem. Soc. 88 (4): 589-593. DOI: $10.1007 / \mathrm{s} 11746-010-1689-4$

Poli B.M., Parisi G., Zampacavallo G., Mecatti M., Lupi P., Gualtieri M. \& Franci O. 2001. Quality outline of European sea bass (Dicentrarchus labrax) reared in Italy: shelf life, edible yield, nutritional and dietetic traits. Aquaculture 202 (3/4): 303-315. DOI: 10.1016/S0044-8486(01)00780-3

Sahena F., Zaidul I.S.M., Jinap S., Saari N., Jahurul H.A., Abbas K.A. \& Norulaini N.A. 2009. PUFAs in fish: Extraction, fractionation, importance in health. Comreh. Rev. Food Sci. Food Safe. 8 (2): 59-74. DOI: 10.1111/j.1541-4337.2009.00069.x

Sargent J.R., Tocher D.R. \& Bell J.G. 2002. The Lipids, Chapter 4, pp. 182-259. In: Halver J.E. \& Hardy R.W. (eds), Fish Nutrition, Third ed., Academic Press, New York, 824 pp. ISBN10: 0123196523, ISBN-13: 978-0123196521

Selmi S., Mbarki R. \& Sadok S. 2008. Seasonal change of lipid and fatty acid composition of little tuna Euthynnus alletteratus by-products. Nutrition and Health 19 (3): 189-194. PMID: 19009740

Sun T., Pigott G.M. \& Herwig R.P. 2002. Lipase-assisted concentration of n-3 polyunsaturated fatty acids from viscera of farmed Atlantic salmon (Salmo salar L.). J. Food Sci. 67 (1): 130-136. DOI: 10.1111/j.1365-2621.2002.tb11372.x

Received May 11, 2012 Accepted November 12, 2012 